\title{
Patient-derived tumor xenografts of lung squamous cell carcinoma alter long non-coding RNA profile but not responsiveness to cisplatin
}

\author{
DAPENG LU ${ }^{1 *}$, PENG LUO $^{1 *}, \mathrm{JU}_{\text {ZHANG }}{ }^{1}$, YUANYUAN YE $^{2}$, QI WANG $^{1}$, MING LI $^{1}$, \\ HANGCHENG ZHOU ${ }^{3}$, MINGRAN XIE ${ }^{4}$ and BAOLONG WANG ${ }^{1}$
}

\begin{abstract}
${ }^{1}$ Department of Clinical Laboratory, Affiliated Provincial Hospital of Anhui Medical University, Hefei, Anhui 230001; ${ }^{2}$ School of Life Sciences, University of Science and Technology of China, Hefei, Anhui 230026; Departments of ${ }^{3}$ Pathology and ${ }^{4}$ Thoracic Surgery, Affiliated Provincial Hospital of Anhui Medical University, Hefei, Anhui 230001, P.R. China
\end{abstract}

Received November 3, 2017; Accepted March 20, 2018

DOI: $10.3892 / \mathrm{ol} .2018 .8401$

\begin{abstract}
Lung squamous cell carcinoma (LSCC), the second most common type of lung cancer, has received limited attention. Patient-derived tumor xenografts (PDTXs) are useful preclinical models to reproduce the diverse heterogeneity of cancer, but it is important to identify potential variations during their establishment. A total of 18 PDTXs were established from 37 the surgical specimens and 16 were serially passaged to third generation. Second- and third-generation xenografts had a faster growth rate in mice. The tumor implantation success rate was associated with poorer differentiation, larger tumor volume and higher expression of Ki-67. The xenografts largely retained histological and key immunophenotypic features (including p53, p63, cytokeratin5/6, and E-cadherin). However, increased Ki-67 expression was identified in partial xenografts. Long non-coding RNA (lncRNA) and mRNA expression in third-generation xenografts differed from that of matched primary tumors. Gene Ontology and pathway analysis showed that mRNAs involved in cell cycle, and metabolism regulation were generally upregulated in xenografts, while those associated with immune responses were typically downregulated. Furthermore, the responses of xenografts to cisplatin were consistent with clinical outcome. In the present study, PDTXs of SCC were successfully established, and closely resembled their original tumor regarding their immunophenotype and response to cisplatin. Overall,
\end{abstract}

Correspondence to: Professor Baolong Wang, Department of Clinical Laboratory, Affiliated Provincial Hospital of Anhui Medical University, 17 Lujiang Road, Hefei, Anhui 230001, P.R. China

E-mail: wbl196555@163.com

*Contributed equally

Key words: lung squamous cell carcinoma, patient-derived tumor xenograft, gene expression, cell proliferation, cisplatin, athymic nude mice
PDTXS of LSCC altered the lncRNA profile and increased the proliferative activity of cancer cells, whilst retaining responsiveness to cisplatin.

\section{Introduction}

Reproducing the diverse heterogeneity of cancer in preclinical models is important in mechanistic and functional studies of tumor biology. Studying drug resistance mechanisms and identifying biomarkers of therapeutic responses and biological targets for treatment will be of increasing importance in the future for individualized management. Among cancer types, lung cancer has the highest global incidence and mortality. Non-small cell lung cancer (NSCLC), which mainly comprises adenocarcinoma (ADC) and squamous cell carcinoma (SCC), accounts for approximately $85 \%$ of all lung cancer cases and has a 5-year survival rate of less than $20 \%$ (1-3). More recent studies have mainly focused on lung ADC. However, SCC, a subgroup representing the second most common type of lung cancer, accounts for over 30\% of NSCLC (4) but has received limited attention. Traditionally, tumor biology studies have been conducted mainly in cancer cell lines grown in vitro or implanted into immunocompromised mice (e.g., nude, SCID, or NOD/SCID mice) (5). Moreover, relatively few SCC cell lines have been established (6). The limitations of these models, including increased homogeneity following long-term culture of established cell lines in vitro, and cell line xenograft tumors rarely exhibiting the tissue architecture of the original cancer, have become apparent (7). Therefore, cell line xenograft tumors frequently fail to adequately predict the efficacy of anticancer agents in the clinic (8).

In theory, patient-derived tumor xenografts (PDTXs), which are established by collecting fresh tissue specimens from cancer patients and directly implanting them into immunocompromised mice, may represent more realistic preclinical models as they closely resemble the tissue architecture of primary tumors, including interactions between other cell types such as the stroma and endothelium (9). To date, several PDTX models have been reported, including for NSCLC. These model-related studies have demonstrated 
that PDTXs largely retain the principal histological features and recapitulate the molecular characterization of cancer biology $(6,10-12)$. However, most have investigated overall similarity between tumor and xenograft rather than differences, which is the focus in the current study.

Long non-coding RNA (lncRNA) is a heterogeneous class of transcripts with a minimum length of 200 bases and limited protein-coding ability $(13,14)$. However, increasing evidence indicates that lncRNAs can affect multiple cellular functions and participate in diverse physiological and pathological processes $(15,16)$. Moreover, emerging evidence supports the notion that aberrant expression of lncRNAs plays a significant role in various human malignant diseases, including NSCLC (17-22). For this reason, we compared xenograft lncRNA profiles with those from corresponding human tumors.

\section{Materials and methods}

Patients and tissue samples. Thirty-seven fresh tumor samples were obtained at initial surgery from patients with pathologically confirmed SCC between July 2013 and November 2014. No patient had received chemotherapy or radiation therapy prior to surgery. Tumor samples and clinical records were obtained from patients with their written informed consent and the study was approved by the Anhui Provincial Hospital Ethical Committee. The quality of the tumor samples was assessed by histological evaluation, and tumor tissue accounted for at least $50 \%$ of the sample. Sections of resected tumor samples for the establishment of PDTX were immediately placed at $4^{\circ} \mathrm{C}$ in RPMI-1640 solution (HyClone; GE Healthcare Life Sciences, Logan, UT, USA) containing penicillin/streptomycin. Other tissue for hematoxylin and eosin (H\&E) staining and immunohistochemistry (IHC) was processed by frozen sectioning and paraffin, and the remaining tissue was immediately cryopreserved in liquid nitrogen and stored at $-80^{\circ} \mathrm{C}$ for future investigation.

Mouse use and care. Female 6-8-week-old Balb/c athymic nude mice (SLRC Laboratory, Shanghai, China) were housed in a pathogen-free environment and provided with sterile water, food, and litter. Cages were replaced once per week, and temperature $\left(24 \pm 2^{\circ} \mathrm{C}\right)$ and humidity $(55 \pm 5 \%)$ were controlled. All animal experiments were approved by the Anhui Provincial Hospital Ethical Committee and were carried out in accordance with the Guidelines for the Care and Use of Laboratory Animals.

Establishment of PDTX models. The fresh tumor samples were placed into sterile Petri dishes, washed three times with phosphate-buffered saline (PBS), and cut into $3 \mathrm{~mm}^{3}$ fragments. Tumor fragments were implanted subcutaneously into the left and right flanks of mice (3-5 mice/patient specimen) and were monitored weekly using Vernier calipers when the implanted tissue was palpable, with the volume calculated as (length $\mathrm{x}$ width2)/2. When the volume of tumor was $500 \mathrm{~mm}^{3}$ in any area of the mouse, the primary tumor $(\mathrm{P})$ was considered to have formed a xenograft tumor (X) and designated ' $\mathrm{X}-1$,' or not from xenograft tumors (no-X) if growth was not detected by 4 months after implantation. Successfully engrafted mice were euthanized and the tumor $(\mathrm{X}-1)$ was removed for serial transplantation to the next generation (X-2, X-3). Following removal of the tumor, necropsy was performed to determine the sites of tumor metastasis (including lymph nodes, liver, and spleen). At each xenograft passage, tumors were harvested, measured, fixed for histopathologic analysis, cryopreserved (in $90 \%$ fetal bovine serum and $10 \%$ DMSO), and snap-frozen in liquid nitrogen for future investigation.

Histology and IHC. Paraffin-embedded tissue blocks from primary and xenograft tumors were cut into $4 \mu \mathrm{m}$ sections. The sections were dewaxed in xylene, dehydrated in a graded alcohol series, and stained with $\mathrm{H} \& \mathrm{E}$ for histological examination. Molecular marker expression was assessed using IHC. Prior to application of the primary antibody, sections were dewaxed and dehydrated, and antigen retrieval was accomplished by heating in an autoclave according to the antibody manufacturer's instructions. Endogenous peroxidase activity was blocked with $3 \% \mathrm{H}_{2} \mathrm{O}_{2}$. After processing, sections were incubated overnight at $4^{\circ} \mathrm{C}$ with primary antibodies against p53, p63, Ki-67, cytokeratin5/6, and E-cadherin (ZsBio, Beijing, China). Sections were subsequently treated with secondary antibody conjugated with horseradish peroxidase polymer and DAB substrate according to the manufacturer's instructions. Next, the slides were counterstained with hematoxylin and evaluated by two pathologists using standard light microscopy. The proportion of stained tumor cells was assessed by counting at least 1,000 cells in randomly selected x400 magnification fields.

\section{LncRNA microarray and computational analysis}

Samples. Total RNA was extracted using TRIzol reagent (Invitrogen; Thermo Fisher Scientific, Inc., Waltham, MA, USA) according to the manufacturer's protocol. RNA quantity and quality were measured with a NanoDrop ND-1,000 spectrophotometer (PeqLab, Erlangen, Germany). RNA integrity was assessed by standard denaturing agarose gel electrophoresis.

RNA microarray. The Arraystar Human LncRNA Microarray V3.0 is designed for the global profiling of human LncRNAs and protein-coding transcripts, and can detect 30,586 LncRNAs and 26,109 coding transcripts. The LncRNAs are carefully constructed using established public transcriptome databases (e.g., Refseq, UCSC knowngenes, Gencode) as well as landmark publications. Each transcript is represented by a specific exon or splice junction probe which can identify individual transcripts accurately. Positive probes for housekeeping genes and negative probes are also printed onto the array for hybridization quality control.

RNA labeling and array hybridization. Sample labeling and array hybridization were performed according to the Agilent One-Color Microarray-Based Gene Expression Analysis protocol (Agilent Technologies, Inc., Santa Clara, CA, USA) with minor modifications. Briefly, mRNA was purified from total RNA after removal of rRNA (mRNA-ONLY ${ }^{\mathrm{TM}}$ Eukaryotic mRNA Isolation kit; Epicentre; Illumina, Inc., San Diego, CA, USA). Then, each sample was amplified and transcribed into fluorescent cRNA along the entire length of the transcripts without 3 ' bias utilizing a random priming method (Arraystar Flash RNA Labeling kit; Arraystar, Rockville, MD, USA). The labeled cRNAs were purified 
Table I. Primer sequences used in this study.

\begin{tabular}{lll}
\hline Target ID & \multicolumn{1}{c}{ Forward primer } & \multicolumn{1}{c}{ Reverse primer } \\
\hline NRG1 & CACTGGGACAAGCCATCTT & AAGCACTCCCCTCCATTCA \\
CDC16 & GGTCTTAGGCGAGATGATACA & AATCCCACGGAGGTGAAATA \\
CCL20 & GCGCAAATCCAAAACAGAC & CCATTCCAGAAAAGCCACA \\
HLA-DPB1 & CGGAGTAAGACATTGACGGG & GGAGCCAGATGCTAACGAA \\
-actin & GTGGCCGAGGACTTTGATTG & CCTGTAACAACGCATCTCATATT
\end{tabular}

NRG1, neuregulin 1; CDC16, cell division cycle 16; CCL20, C-C motif chemokine ligand 20; HLA-DPB1, major histocompatibility complex class II DP $\beta 1$.

with an RNeasy Mini kit (Qiagen GmbH, Hilden, Germany). The concentration and specific activity of the labeled cRNAs (pmol Cy3/ $\mu \mathrm{g}$ cRNA) were measured by NanoDrop ND-1,000. Next, $1 \mu \mathrm{g}$ of each labeled cRNA was fragmented by adding $5 \mu \mathrm{l}$ of $10 \mathrm{X}$ blocking agent and $1 \mu \mathrm{l}$ of $25 \mathrm{X}$ fragmentation buffer, heating the mixture at $60^{\circ} \mathrm{C}$ for $30 \mathrm{~min}$, and adding $25 \mu 12 \mathrm{X}$ GE hybridization buffer to dilute the labeled cRNA. Hybridization solution $(50 \mu \mathrm{l})$ was dispensed into the gasket slide and assembled with the LncRNA expression microarray slide. The slides were incubated for $17 \mathrm{~h}$ at $65^{\circ}$ in an Agilent hybridization oven. The hybridized arrays were washed, fixed, and scanned using an Agilent DNA Microarray Scanner (G2505C; Agilent Technologies, Inc.).

Data analysis. Agilent Feature Extraction software (version 11.0.1.1; Agilent Technologies, Inc.) was used to analyze the acquired array images. Quantile normalization and subsequent data processing were performed using the Gene Spring GX v12.1 software package (Agilent Technologies, Inc.). After quantile normalization of the raw data, LncRNAs and mRNAs from at least 6 out of 12 samples with flags in Present or Marginal ('All Targets Value') were chosen for further data analysis. Differentially expressed LncRNAs and mRNAs with statistical significance between the two groups were identified through $\mathrm{P}$-value/FDR filtering $(\mathrm{P}<0.05)$. Differentially expressed LncRNAs and mRNAs between two samples were identified through fold-change filtering (fold-change $>2.0$ ). Hierarchical clustering and combined analysis were performed using homemade scripts.

Reverse transcription-quantitative polymerase chain reaction (RT-qPCR) analysis. To validate the selected mRNA expression levels in primary tumors compared with third generation xenograft tumors, RT-qPCR analysis was applied. $\beta$-actin was used as an internal control. The primers used are listed in Table I. RT-qPCR was performed using the SYBR-Green (Takara Biotechnology Co., Ltd., Dalian, China) dye detection method on an ABI 7500 PCR instrument under the following conditions: $95^{\circ} \mathrm{C}$ for $10 \mathrm{~min}$, and 40 cycles of $95^{\circ} \mathrm{C}$ for $10 \mathrm{~min}$ and $60^{\circ} \mathrm{C}$ for $60 \mathrm{sec}$. Relative gene expression levels were analyzed by the $2^{-\Delta \Delta \mathrm{Cq}}$ method as previously reported (23), where $\Delta \mathrm{Cq}=\mathrm{Cq}_{\text {target }}-\mathrm{Cq}_{\beta \text {-actin }}$.

Chemosensitivity testing. For chemotherapeutic response assays, second-generation xenograft tumor fragments were subcutaneously transplanted in 6-8-week-old female mice. When tumor volume reached $50-200 \mathrm{~mm}^{3}$, 3-5 mice were randomly assigned to treatment or control groups. Cisplatin (20 mg/ml; Jiangsu Hansoh Pharmaceutical Co., Ltd., Jiangsu, China) preparations were diluted to $0.5 \mathrm{mg} / \mathrm{ml}$ in saline and administered weekly $(5 \mathrm{mg} / \mathrm{kg} / \mathrm{d}$, i.p.) to treatment group xenograft tumors for 3 weeks. Control mice were injected with an equivalent volume of saline. The injection volume was $0.2 \mathrm{ml} / 20 \mathrm{~g}$ body weight. Tumor volume was monitored weekly using Vernier calipers and tumor volume was calculated as for the establishment of PDTXs. Relative tumor volume (RTV) and antitumor activity were calculated as previously described (24). Briefly, $\mathrm{RTV}=(\mathrm{Vx} / \mathrm{V} 1)$, where $\mathrm{Vx}$ is the tumor volume on day $\mathrm{x}$ and $\mathrm{V} 1$ is the tumor volume upon initiation of therapy (day 1). Antitumor activity was evaluated according to tumor growth inhibition, percentage of growth inhibition=100-(RTVt/RTVcx100), where RTVt is the mean RTV of treatment groups and RTVc is the mean RTV of control groups. Tumor growth inhibition of $50 \%$ was considered a meaningful biological effect.

Statistical analysis. The unpaired two-tailed t-test, Wilcoxon rank sum test or Chi-square test were used to determine the association of individual tumor features with engraftment. The proportions of Ki-67 stained tumor cells were presented as means \pm standard deviation and analyzed using Student's t-test. $\mathrm{P}<0.05$ was considered to indicate a statistically significant difference. Statistical analyses were carried out using the statistical analysis package SPSS version 11.0 (SPSS, Inc., Chicago, IL, USA).

\section{Results}

Xenograft engraftment was associated with tumor size, differentiation, and expression of Ki-67. To establish the PDTXs, surgically resected samples from 37 SCC patients were each implanted subcutaneously into 3-5 athymic nude mice within $1 \mathrm{~h}$ of resection. Individual patient data and tumor histopathology are presented in Table II. We successfully established 18 PDTXs (engraftment rate 48.6\%, 18/37). The characteristics of primary tumors that did or didn't form xenografts (X or no-X) were compared retrospectively. Results showed that tumor engraftment was not dependent on patient's age, smoking history, or tumor pathological characteristics such as tumor TNM stage, grade, and lymph node metastasis. 
Table II. Clinical materials of 37 lung squamous cell carcinoma patients and histopathology of their tumors.

\begin{tabular}{|c|c|c|c|c|c|c|}
\hline Cases & Age/sex & $\begin{array}{l}\text { TNM } \\
\text { stage }\end{array}$ & Differentiation & Smoking & $\begin{array}{c}\mathrm{LN} \\
\text { metastasis }\end{array}$ & $\begin{array}{l}\text { Xenograft } \\
\text { formation }^{\mathrm{a}}\end{array}$ \\
\hline 1 & $58 / \mathrm{M}$ & II & Poor & No & No & Yes \\
\hline 2 & $70 / \mathrm{M}$ & II & Poor & No & No & Yes \\
\hline 3 & $58 / \mathrm{M}$ & III & Poor & No & Yes & Yes \\
\hline 4 & $65 / \mathrm{M}$ & II & Poor & Yes & No & Yes \\
\hline 5 & $57 / \mathrm{M}$ & III & Poor & No & No & Yes \\
\hline 6 & $72 / \mathrm{M}$ & I & Poor & Unknown & No & Yes \\
\hline 7 & $59 / \mathrm{M}$ & III & Poor & No & Yes & Yes \\
\hline 8 & $60 / \mathrm{M}$ & I & Poor & No & No & Yes \\
\hline 9 & $73 / \mathrm{M}$ & II & Moderate & Yes & No & Yes \\
\hline 10 & $70 / \mathrm{M}$ & III & Poor & Yes & No & Yes \\
\hline 11 & $61 / \mathrm{M}$ & III & Poor & No & Yes & Yes \\
\hline 12 & $67 / \mathrm{M}$ & III & Poor & Yes & Yes & Yes \\
\hline 13 & $73 / \mathrm{M}$ & III & Moderate & Yes & Yes & Yes \\
\hline 14 & $64 / \mathrm{M}$ & I & Moderate & No & No & Yes \\
\hline 15 & $51 / \mathrm{M}$ & $\mathrm{I}$ & Poor & Yes & No & Yes \\
\hline 16 & 77/M & II & Poor & No & No & Yes \\
\hline 17 & $65 / \mathrm{M}$ & $\mathrm{I}$ & Moderate & Yes & No & Yes \\
\hline 18 & $55 / \mathrm{M}$ & III & Poor & No & Yes & Yes \\
\hline 19 & $56 / \mathrm{M}$ & III & Moderate & Yes & Yes & No \\
\hline 20 & 75/M & II & Moderate & Yes & No & No \\
\hline 21 & $72 / \mathrm{M}$ & III & Poor & Unknown & Yes & No \\
\hline 22 & $74 / \mathrm{M}$ & I & Poor & Yes & No & No \\
\hline 23 & $69 / \mathrm{M}$ & I & Moderate & No & No & No \\
\hline 24 & 71/M & II & Moderate & Yes & No & No \\
\hline 25 & 71/M & II & Moderate & No & No & No \\
\hline 26 & $59 / \mathrm{M}$ & III & Moderate & Yes & Yes & No \\
\hline 27 & 69/M & II & Moderate & Yes & Yes & No \\
\hline 28 & 72/M & I & Moderate & Yes & No & No \\
\hline 29 & $73 / \mathrm{M}$ & IV & Poor & Yes & No & No \\
\hline 30 & $64 / F$ & I & Moderate & No & No & No \\
\hline 31 & $63 / \mathrm{F}$ & I & Moderate & No & No & No \\
\hline 32 & $69 / \mathrm{M}$ & III & Moderate & Yes & Yes & No \\
\hline 33 & $59 / \mathrm{M}$ & I & Poor & No & No & No \\
\hline 34 & $70 / \mathrm{M}$ & II & Poor & Yes & No & No \\
\hline 35 & 49/M & III & Moderate & Yes & Yes & No \\
\hline 36 & $60 / \mathrm{M}$ & I & Moderate & Unknown & No & No \\
\hline 37 & $66 / \mathrm{M}$ & II & Moderate & Unknown & No & No \\
\hline
\end{tabular}

${ }^{a}$ Whether or not the primary tumor was able to be used to form a xenograft tumor. TNM, tumor node metastasis; LN, lymph node; M, male; $\mathrm{F}$, female.

However, tumors that formed xenografts had a larger median tumor volume ( 87.5 vs. $15.8 \mathrm{~cm}^{3}, \mathrm{P}<0.001$; Table III). Poorly differentiated tumors were notably easier to engraft than moderately differentiated tumors ( 73.7 vs. $22.2 \%, \mathrm{P}=0.002$; Table III). In multivariate analysis, poor differentiation and larger tumor volume were independently associated with increased rates of engraftment. Therefore, we speculate that the primary tumors which formed xenografts might contain higher numbers of actively proliferating cancer cells. Ki-67 is a nuclear protein expressed by proliferating cells. The labeling index of $\mathrm{Ki}-67$ was determined in tumor samples by IHC. As expected, the $\mathrm{X}$ group had a higher proportion of tumor cells stained by $\mathrm{Ki}-67$ than the no-X group (58.6 \pm 22.0 vs. $27.4 \pm 24.3 \%, \mathrm{P}<0.001$; Fig. 1).

Passaged xenografts proliferated faster than first-generation xenografts. Among the 18 successfully established xenografts, 16 were passaged to second generation (engraftment rate 
Table III. Association between tumorigenicity of SCC in nude mice and the clinicopathological parameters of patients.

\begin{tabular}{|c|c|c|c|}
\hline Clinicopathological parameter & $X(n=18)$ & No-X $(n=19)$ & P-value \\
\hline Age, years & $64.2 \pm 7.3$ & $66.4 \pm 7.0$ & $0.136^{\mathrm{a}}$ \\
\hline Median tumor volume, $\mathrm{cm}^{3}(25 \%, 75 \%)$ & $87.5(44.8,130.5)$ & $15.8(6.0,48.0)$ & $<0.001^{\mathrm{b}}$ \\
\hline TNM stage & & & $0.484^{\mathrm{c}}$ \\
\hline I & $5(27.8)$ & $8(42.1)$ & \\
\hline II & $5(27.8)$ & $6(31.6)$ & \\
\hline III/IV & $8(44.4)$ & $5(26.3)$ & \\
\hline Differentiation & & & $0.002^{\mathrm{c}}$ \\
\hline Moderate & $4(22.2)$ & $14(73.7)$ & \\
\hline Poor & $14(77.8)$ & $5(26.3)$ & \\
\hline Smoking & & & $0.286^{\mathrm{c}}$ \\
\hline Yes & $7(38.9)$ & $10(52.6)$ & \\
\hline No & $10(55.6)$ & $6(31.6)$ & \\
\hline Unknown & $1(5.6)$ & $3(15.8)$ & \\
\hline Lymph node metastasis & & & $0.641^{\mathrm{c}}$ \\
\hline Positive & $6(33.3)$ & $5(26.3)$ & \\
\hline Negative & $12(66.7)$ & $14(73.7)$ & \\
\hline
\end{tabular}

$\mathrm{X}$, Primary tumor tissues that could form xenograft tumors in nude mice; No-X, Primary tumor tissues that could not form xenograft tumors in nude mice. P-value calculated by ${ }^{a}$ unpaired two-tailed t-test, ${ }^{b}$ Wilcoxon rank sum test or ${ }^{\mathrm{c}}$ Chi-square test of variance. TNM, tumor node metastasis; SCC, squamous cell carcinoma.
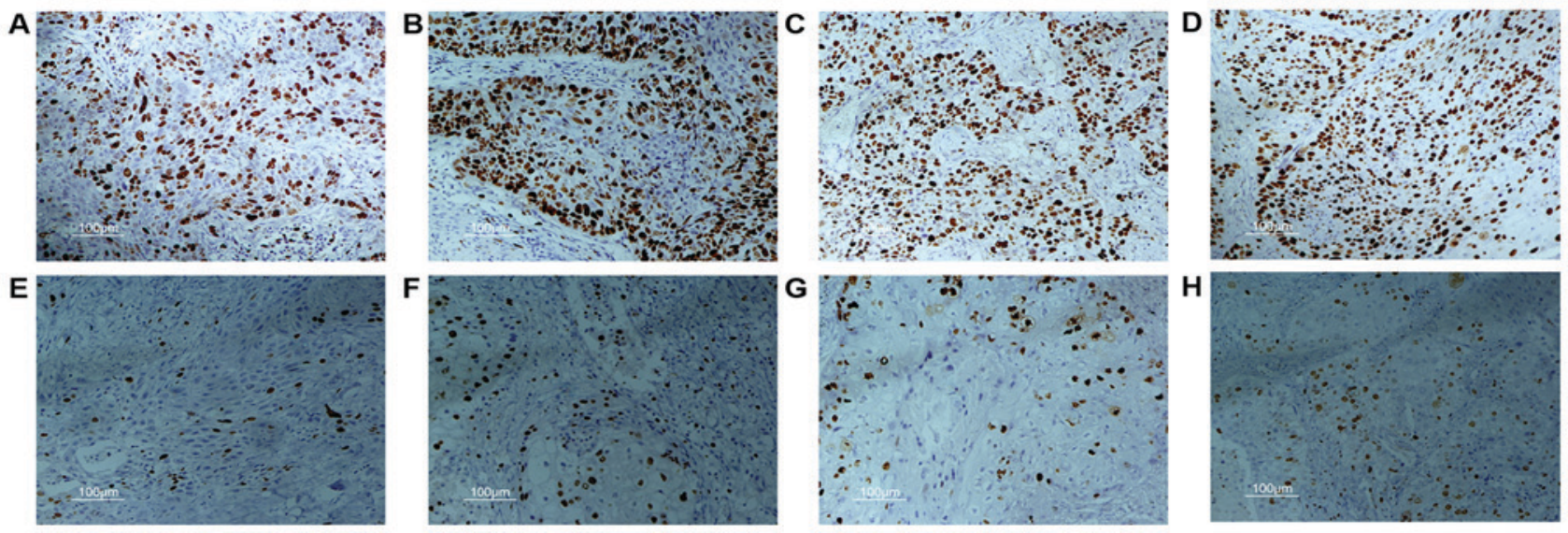

Figure 1. Comparison of Ki-67 expression in X group and no-X group. Difference of Ki-67 expression between primary lung squamous cell carcinoma tissues which could form xenograft tumors [(A-D) $X$ group, $n=4]$ and could not form xenograft tumors [(E-H) no-X group, $n=4]$ in mice was detected by immunohistochemistry. The proportion of tumour cells stained by Ki-67 in $\mathrm{X}$ group was significantly higher than that in no- $\mathrm{X}$ group $(58.6 \pm 22.0$ vs. $27.4 \pm 24.3 \%$, $\mathrm{n}=37$, $\mathrm{P}<0.001)$. Scale bars, $100 \mu \mathrm{m}$.

of $89 \%)$ and all 16 sec-generation xenografts were serially passaged to third generation (engraftment rate of $100 \%$ ). A comparison between primary tumors and the corresponding xenograft tumors revealed similar histological architecture within three passages, particularly in terms of cell type and grade of nuclear atypia (Fig. 2, H\&E). However, second-generation xenograft tumors required significantly less time to reach a size of $500 \mathrm{~mm}^{3}$ compared with first-generation tumors (average time of 6.8 and 9.2 weeks, respectively, $\mathrm{P}<0.001$ ), but the difference between the second and third generation was not significant (average time of 6.3 and 6.8 weeks, respectively, $\mathrm{P}>0.05$ ), which suggested that passaged xenografts were more proliferative than the first-generation tumor and that PDTXs had increased proliferative activity of cancer cells. Moreover, for primary tumors obtained from six patients with lymph node metastasis, as a result of short time and relatively small numbers of mice, all xenograft tumors showed only local growth, without distant metastasis at autopsy.

PDTXs largely retained histological and key immunophenotypic features apart from increased expression of Ki-67 in primary tumors with relatively low expression. Whether PDXTs suitable for the preclinical studies, 12 representative xenograft tumors and matched primary tumors were 


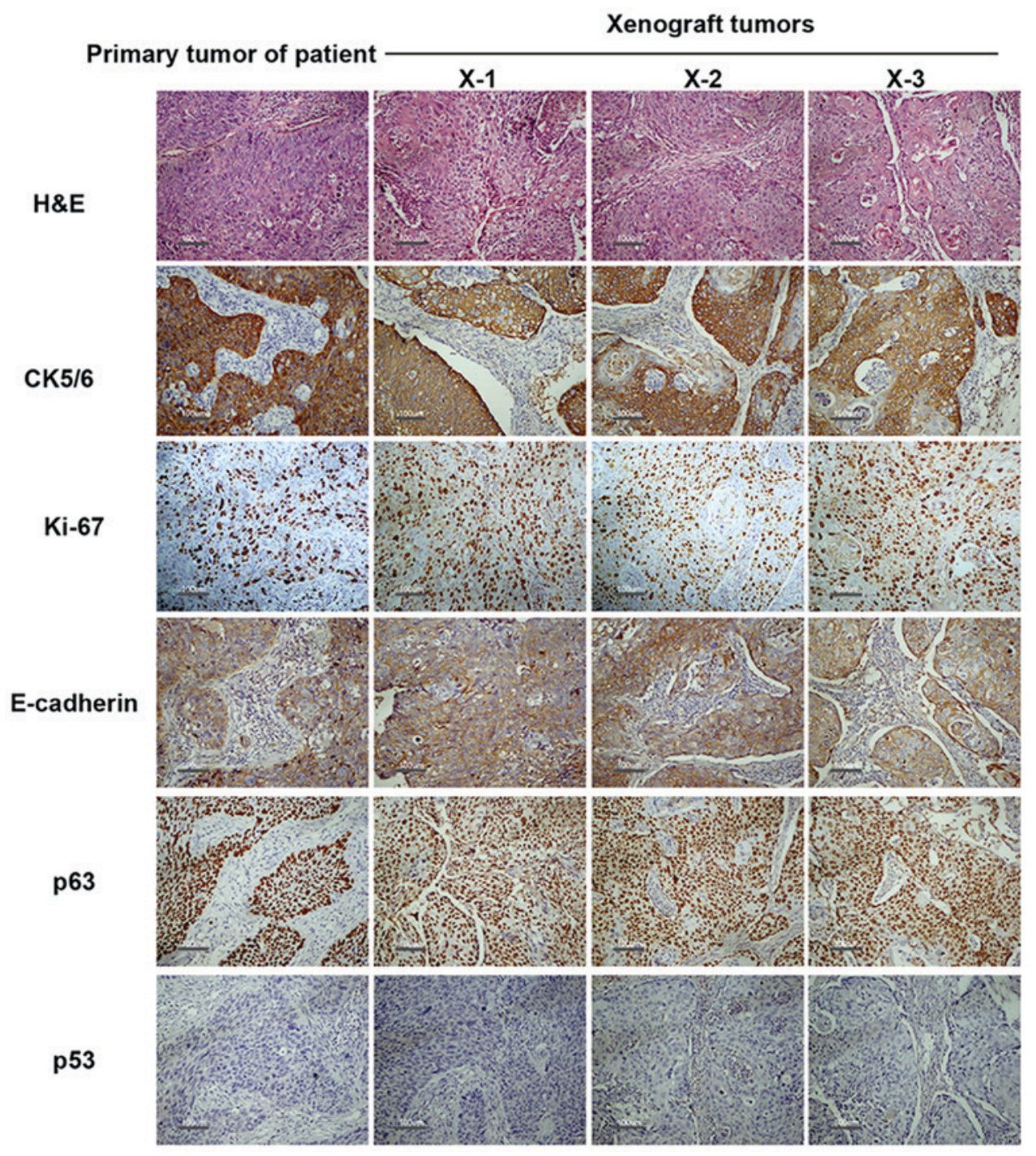

Figure 2. Representative findings of each histology/immunophenotypic in each passage. Histology and tumor molecular markers (p53, p63, Ki-67, cytokeratin5/6 and E-cadherin) expression of primary tumor (P) and corresponding xenograft tumors (X-1, X-2 and X-3) were detected by H\&E and IHC. No major differences are seen in the tumor structure and cancer molecular markers expression between the primary tumor and the xenograft tumors except Ki-67. In the case of Ki-67 expression, compared with $\mathrm{P}$, an increase was observed in X-1 and also in serially passages (X-2, X-3), suggesting a more proliferative phenotype characterized by over expression of Ki-67. Scale bars, $100 \mu \mathrm{m}$. X-1, X-2 and X-3 represents the first, second and third generation xenograft tumor, respectively.

evaluated by IHC for markers of proliferation (p53 and Ki-67), aggressiveness (E-cadherin), and differentiation (p63 and cytokeratin5/6). A representative sample is shown in Fig. 2, and the overall expression of E-cadherin, p53, p63, and cytokeratin5/6 in primary tumors was highly similar to that in matched xenograft tumors. Furthermore, in general, the primary and xenograft tumors shared a strong expression of Ki-67 (proportion of the Ki-67-stained tumor cells $>75 \%$ ). However, some primary tumors (cases 2, 9, 10, 11, 14 and 15) with lower levels of Ki-67 expression (average proportion of $\mathrm{Ki}-67$ stained tumor cells $41.7 \pm 8.8 \%$ ) were observed, but expression was significantly elevated in xenograft tumors $(75.0 \pm 14.0,74.2 \pm 15.6$ and $83.3 \pm 7.5 \%$ for first, second, and third generation, respectively, $\mathrm{P}<0.05$ ). This tendency was particularly pronounced in the third-generation xenograft tumors. Altogether, these data suggest that xenograft tumors maintain the essential immunophenotypic features of the primary tumor, but that in the process of establishing PDTXs, the selection of a more proliferative
Table IV. Correlation coefficient of IncRNAs and mRNAs between primary tumors and corresponding third generation xenografts $(\mathrm{X}-3)$.

\begin{tabular}{lcc}
\hline & \multicolumn{2}{c}{ Correlation coefficient } \\
\cline { 2 - 3 } Cases & lncRNA & mRNA \\
\hline 3 & 0.85 & 0.89 \\
6 & 0.84 & 0.88 \\
9 & 0.79 & 0.83 \\
10 & 0.81 & 0.87 \\
12 & 0.81 & 0.87 \\
15 & 0.85 & 0.89 \\
\hline
\end{tabular}

LncRNAs and mRNAs similarity between primary tumors and corresponding third generation xenografts (X-3) were assessed by determination of Pearson correlation coefficients. LncRNAs, long-noncoding RNAs. 
A

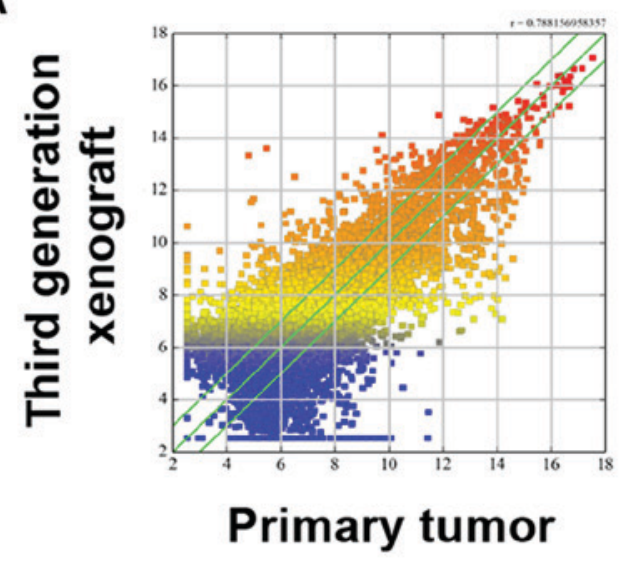

B

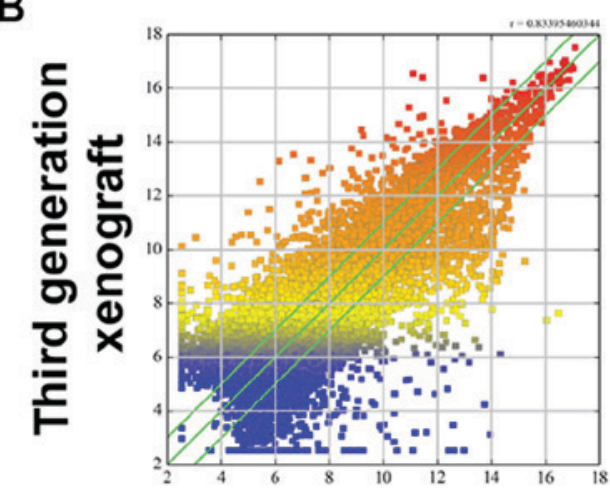

Primary tumor
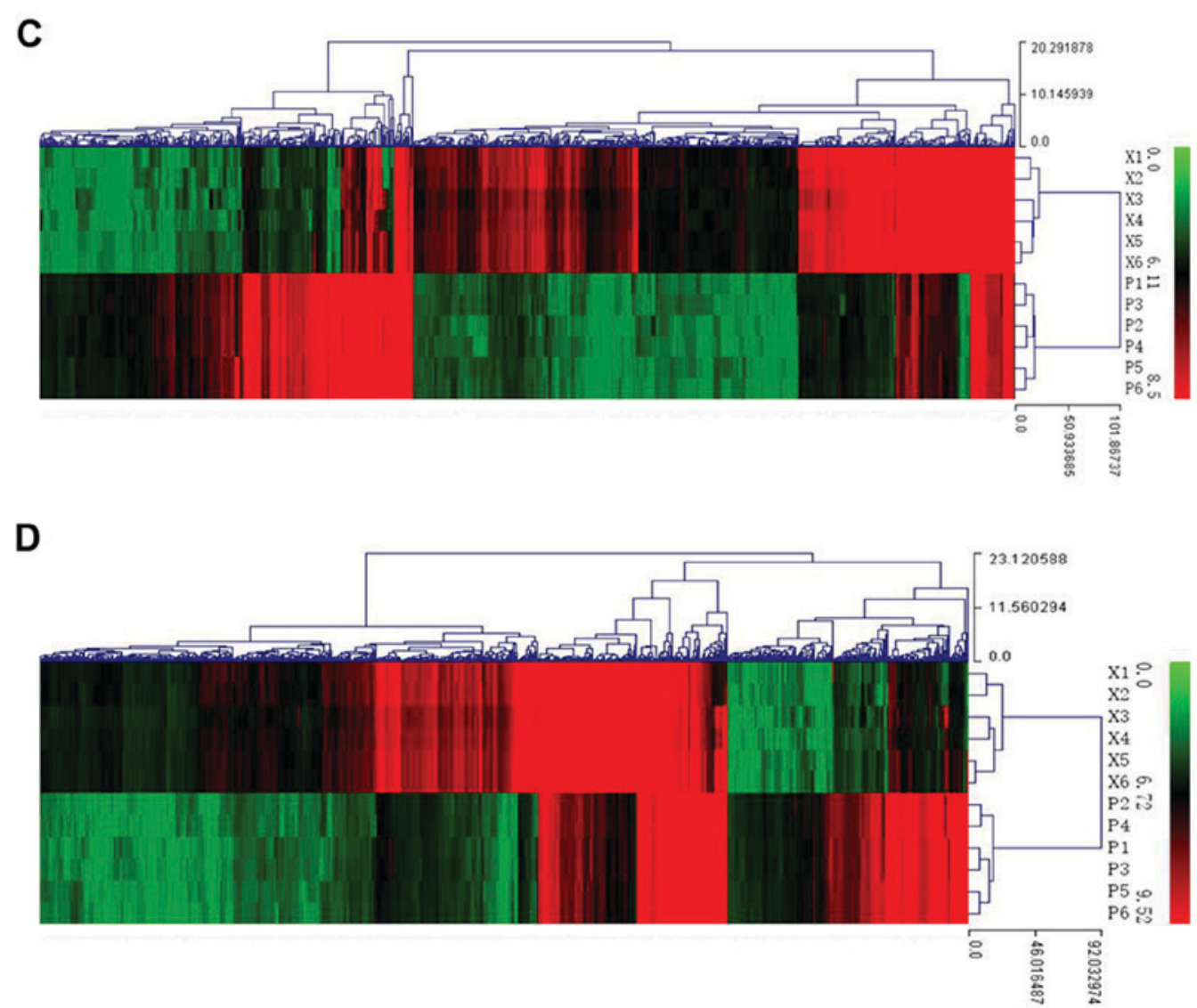

Figure 3. Comparison of gene expression in primary tumors and corresponding third generation PDTXs. The primary tumor and third generation PDTX from one patient for lncRNAs and mRNAs expression were analyzed by Arraystar GeneChip probe arrays. Expression scatter plot of the (A) lncRNAs or (B) mRNAs between the primary tumor $(\mathrm{P})$ and corresponding third generation PDTX (X-3) indicates that the great majority of probes were not differentially expressed and were well correlated between P and X-3. Scatter plot representing 30,586 lncRNAs or 26,109 mRNAs probe sets. However, heat map showing differentially expressed (C) 941 lncRNAs and (D) 695 mRNAs (fold-change $>5.0, P<0.05$ ). Each column represents lncRNA or mRNA, and each row represents a tissue sample. Relative expression values are depicted according to the color scale. Red indicates high relative expression; green indicates low relative expression. lncRNA, long non-coding RNA; PDTX, patient-derived tumor xenograft.

phenotype characterized by overexpression of Ki-67 may be accomplished.

LncRNA and mRNA expression in third-generation xenograft tumors differed from primary tumors. To determine whether the genetic features of xenograft tumors changed during the serial passage of PDTX models, a gene chip study was performed in 6 primary tumors $(\mathrm{P})$ and their corresponding third-generation xenograft tumors (X-3) using an Arraystar probe dataset of 30,586 lncRNAs and 26,109 mRNAs. Linear regression analysis was performed to analyze the lncRNA and mRNA expression patterns in xenograft tumors and primary tumors. Gene expression (including lncRNAs and mRNAs) scatter plots between primary tumors and third-generation xenograft tumors indicated that the majority of probes were not differentially expressed. An example of the correlation between IncRNA and mRNA expression patterns is shown in Fig. 3A and B. The correlation coefficient of lncRNAs between 
Table V. Deregulated mRNAs detected using microarray in 6 primary tumors and corresponding third generation xenografts (X-3).

A, Upregulated in X-3 group

\begin{tabular}{llc}
\hline Seqname & GeneSymbol & Fold-change \\
\hline NM_018661 & DEFB103B & 152 \\
NM_006158 & NEFL & 142 \\
NM_001017920 & DAPL1 & 105 \\
NM_001062 & TCN1 & 104 \\
NM_022097 & CHP2 & 76 \\
NM_001024372 & BAALC & 73 \\
NM_001144940 & VMO1 & 72 \\
NM_001014291 & SPRR2G & 65 \\
NM_001144941 & VMO1 & 56 \\
NM_173178 & IL36B & 52 \\
NM_020958 & PPP4R4 & 51 \\
NM_005557 & KRT16 & 48 \\
NM_001146055 & SNCA & 48 \\
NM_018159 & NUDT11 & 47 \\
ENST00000263182 & BBOX1 & 45 \\
ENST00000315238 & CALML3 & 43 \\
NM_182566 & VMO1 & 40 \\
NM_001144939 & VMO1 & 39 \\
NM_013964 & NRG1 & 39 \\
\hline
\end{tabular}

$\mathrm{B}$, Downregulated in X-3 group

\begin{tabular}{llc}
\hline Seqname & GeneSymbol & Fold-change \\
\hline NM_002196 & INSM1 & 847 \\
NM_153488 & MAGEA2B & 135 \\
NM_006183 & NTS & 123 \\
NM_172313 & CSF3R & 122 \\
NM_001025199 & CHI3L2 & 117 \\
NM_001127592 & FCGR3A & 68 \\
NM_021048 & MAGEA10 & 61 \\
NM_000569 & FCGR3A & 58 \\
NM_006172 & NPPA & 52 \\
NM_018643 & TREM1 & 49 \\
NM_002364 & MAGEB2 & 49 \\
NM_001161728 & PLA2G2A & 44 \\
NM_002338 & LSAMP & 43 \\
NM_001130046 & CCL20 & 41 \\
NM_002121 & HLA-DPB1 & 39 \\
NM_005306 & FFAR2 & 38 \\
NM_015424 & CHRDL2 & 34 \\
NM_003353 & UCN & 34 \\
NM_152997 & FDCSP & 31 \\
\hline
\end{tabular}

$\mathrm{P}$ and X-3 ranged from 0.788 to 0.851 . Similarly, mRNA expression levels were also well correlated between P and X-3 tumors, with a correlation coefficient ranging from 0.834 to 0.895 (listed
Table VI. Deregulated lncRNAs detected using microarray in 6 primary tumors and corresponding third generation xenografts $(\mathrm{X}-3)$.

A, Upregulated in X-3 group

\begin{tabular}{llc}
\hline Seqname & GeneSymbol & Fold-change \\
\hline NR_038340 & LOC100505817 & 184 \\
ENST00000583942 & CTD-2354A18.1 & 118 \\
ENST00000448991 & RP1-214M20.2 & 114 \\
ENST00000435813 & RP11-346D6.6 & 96 \\
uc022cje.1 & CYorf16 & 81 \\
ENST00000584612 & KRT16P2 & 77 \\
ENST00000498616 & RP11-85M11.2 & 74 \\
ENST00000583748 & AC022596.6 & 69 \\
uc001uzl.3 & BC025370 & 66 \\
ENST00000425820 & RP4-694A7.2 & 65 \\
ENST00000425820 & RP4-694A7.2 & 65 \\
TCONS_00010362 & XLOC_004859 & 60 \\
ENST00000576842 & CTD-2034I21.2 & 46 \\
ENST00000579062 & KRT16P2 & 39 \\
NR_024475 & LOC100216001 & 35 \\
ENST00000504916 & RP11-78C3.1 & 35 \\
ENST00000433377 & RP5-866L20.1 & 34 \\
ENST00000526487 & RP11-839D17.3 & 33 \\
ENST00000434541 & AC147651.1 & 30 \\
ENST00000509399 & RP11-297P16.4 & 30 \\
\hline
\end{tabular}

$\mathrm{B}$, Downregulated in X-3 group

\begin{tabular}{llr}
\hline Seqname & \multicolumn{1}{c}{ GeneSymbol } & Fold-change \\
\hline NR_034129 & LOC100128098 & 399 \\
ENST00000451190 & RP11-414K1.3 & 128 \\
ENST00000420058 & RP11-645N11.2 & 94 \\
ENST00000420058 & RP11-645N11.2 & 94 \\
TCONS_00026385 & XLOC_012735 & 68 \\
ENST00000440221 & AL773572.7 & 68 \\
ENST00000440221 & AL773572.7 & 68 \\
ENST00000440221 & AL773572.7 & 68 \\
ENST00000440221 & AL773572.7 & 68 \\
ENST00000451225 & RP11-414K1.3 & 64 \\
uc002ywn.1 & AL109792 & 62 \\
ENST00000429730 & AC079767.4 & 61 \\
uc001gzl.3 & BC034684 & 58 \\
NR_033863 & FLJ41200 & 49 \\
ENST00000470997 & HLA-DPB2 & 43 \\
ENST00000579923 & RP11-106E15.1 & 39 \\
ENST00000538294 & RP11-230G5.2 & 37 \\
ENST00000446557 & RP13-16H11.2 & 36 \\
ENST00000523523 & CTD-2024D23.1 & 26 \\
TCONS_00010211 & XLOC_004680 & 24 \\
\hline & & \\
\hline
\end{tabular}




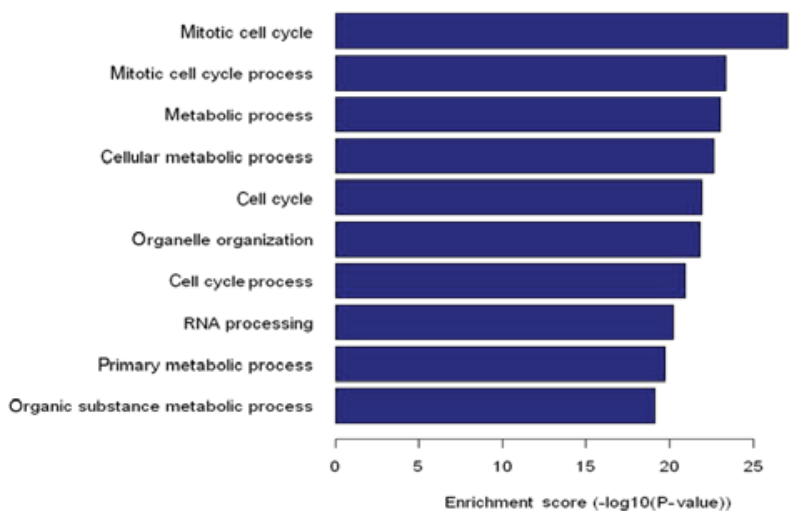

B

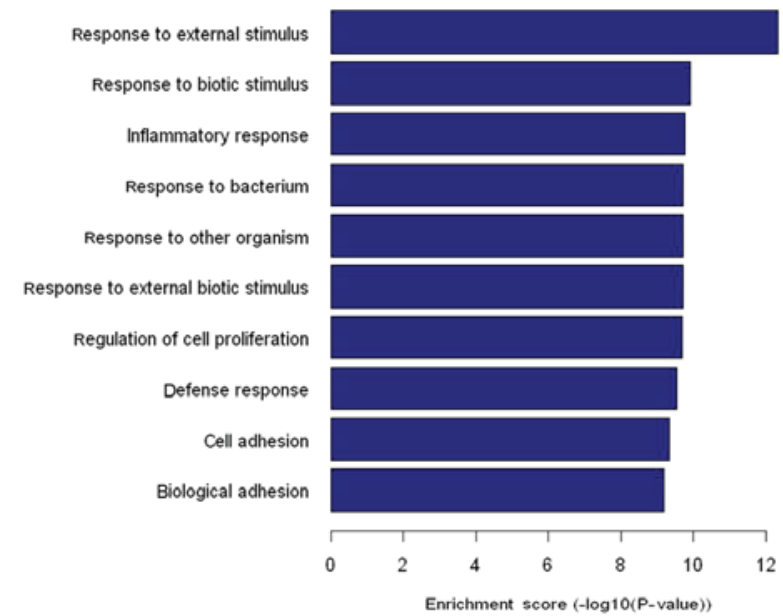

c

Up-regulated mRNAs

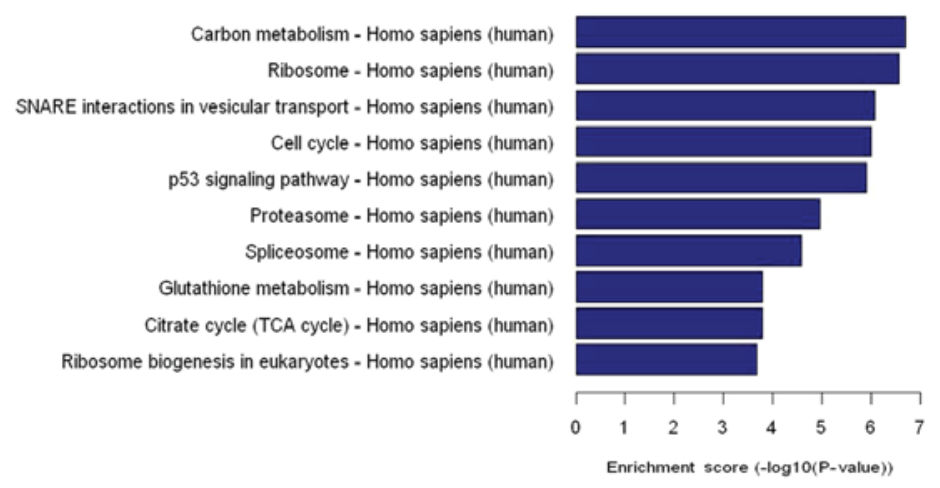

D

Down-regulated mRNAs

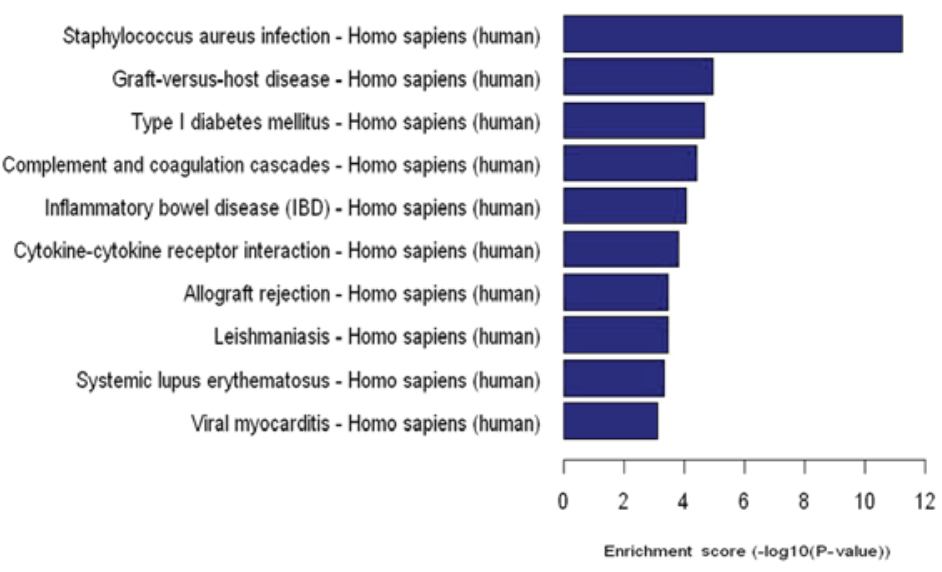

Figure 4. Gene Ontology annotation and pathway analysis of differentially expressed mRNAs. (A) GO analyses showed the upregulated mRNAs were mainly associated with cell cycle and metabolic process; (B) Downregulated mRNAs were mainly associated with immune response and cell adhesion. Bar plot shows the top ten Enrichment Score value of the significant enrichment terms. (C) Enriched pathways corresponded to upregulated mRNAs in xenograft groups including 'Cell cycle', 'p53 singaling pathway', 'Carbon metabolism' and 'Glutathione metabolism' was associated with cell proliferation; (D) Downregulated mRNAs in xenograft groups, which appeared to be responsible for 'Graft-versus-host', 'Allograft rejection' and 'Cytokine-cytokine receptor interaction' was associated with immune-mediated processes. Pathway analysis was predominantly based on the KEGG database. P $<0.05$ using the Fisher's exact test were classed as being statistically significant. The bar plot shows the top ten Enrichment score [-log 10 (P-value)] value of the significant enrichment pathway.

in Table IV). However, lncRNA or mRNA expression profiling in the xenograft tumor and primary tumor was separated into two distinct clusters by unsupervised hierarchical clustering, with all xenograft tumors within the same branch and primary tumors within the other branch. Differentially expressed IncRNAs or mRNAs with statistical significance were identified by Volcano Plot filtering between third-generation xenograft tumors (X-3) and primary tumors (fold-change $>2.0$, $\mathrm{P}<0.05)$. Compared with primary tumors, 2,109 lncRNAs were consistently upregulated and 2,129 lncRNAs were consistently downregulated in the $\mathrm{X}-3$ groups. In addition, the expression of 2,582 mRNAs increased and 1,122 decreased in the X-3 groups. Fold-change analysis between the primary and xenograft tumors revealed 941 differentially expressed lncRNAs (585 upregulated, 356 downregulated) and 695 differentially expressed mRNAs probe sets (474 upregulated, 221 downregulated) with fold-changes $>5.0$. Clustering based on these probe sets showed a clear distinction between primary tumors and xenografts (Fig. 3C and D). The expression levels of the 20 top-ranked lncRNAs and mRNAs (xenograft tumors vs. primary tumors) are listed in Tables V and VI.
Upregulated mRNAs in PDTXs were mainly associated with cell proliferation while downregulated mRNAs appeared to be responsible for immune response. GO analysis showed that upregulated mRNAs in PDTXs were mainly associated with cell cycle and metabolic processes (Fig. 4A), while downregulated mRNAs were mainly involved in the immune response and cell adhesion (Fig. 4B). Similarly, pathway analysis indicated that 45 enriched pathways corresponded to upregulated mRNAs in xenograft groups. Among these, we found that several enriched networks including 'Cell cycle', 'p53 signaling pathway', 'Carbon metabolism', and 'Glutathione metabolism' were associated with cell proliferation (Fig. 4C). In addition, 32 enriched pathways corresponding to downregulated mRNAs in xenograft groups were responsible for 'Graft-versus-host', 'Allograft rejection', and 'Cytokine-cytokine receptor interaction' networks, which are associated with immune-mediated processes (Fig. 4D).

To validate the microarray and pathway analysis results, the expression level of 4 mRNAs (NRG1, CDC16, HLA-DPB1, and CCL-20) thought to play important roles in cell proliferation or immune response were analyzed by RT-qPCR. The 


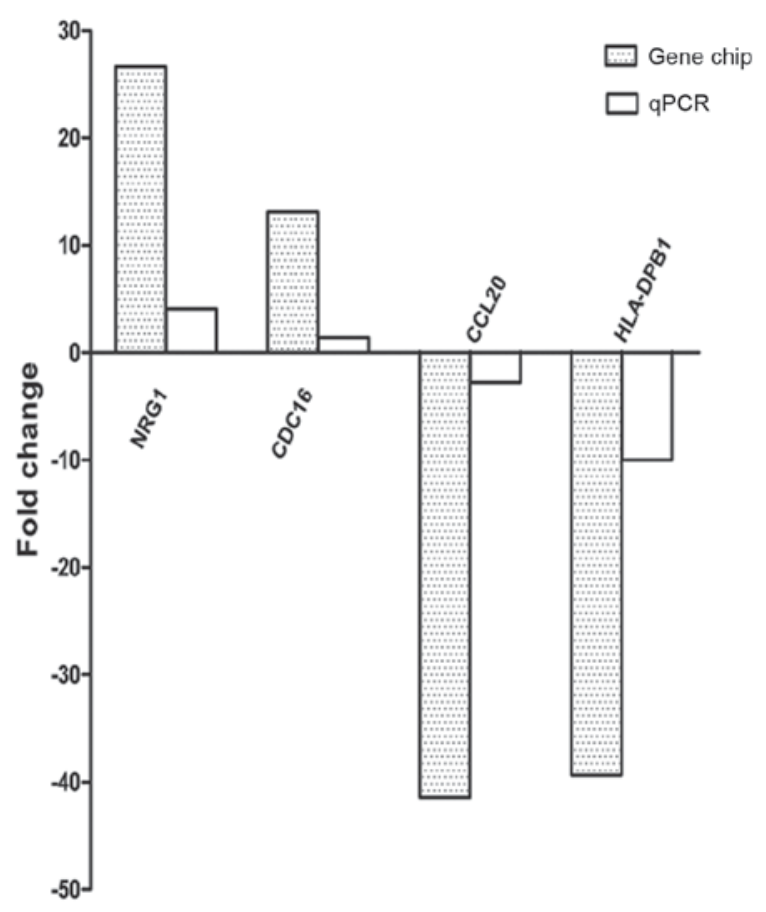

Figure 5. Validation of microarray data by RT-qPCR. Differential expression of the 4 mRNAs in 6 paired primary tumors $(\mathrm{P})$ and corresponding third generation xenograft tumors $(\mathrm{X})$ by microarray was validated by RT-qPCR. Relative expression level in xenograft tumors was normalized by the primary tumors. All the RT-qPCR results were consistent with the gene chip. The heights of the columns in the chart represent the median fold-changes $(\mathrm{X} / \mathrm{P})$ for each of the validated mRNAs. Fold-changes were calculated by the $2^{-\Delta \Delta \mathrm{Cq}}$ method. Fold-changes $=$ mean $2^{-\Delta \mathrm{Cq}}(\mathrm{X}) / \mathrm{mean} 2^{-\Delta \mathrm{Cq}}(\mathrm{P})$, where $\Delta \mathrm{Cq}=\mathrm{Cq}_{\text {target }}-\mathrm{Cq}_{\beta \text {-actin }}$.

expression levels of NRG1 and CDC16 were clearly increased (all P<0.05), while HLA-DPB1 and CCL-20 were dramatically decreased in xenograft tumors (all $\mathrm{P}<0.05$ ). These RT-PCR results were consistent with those observed in the microarray analysis (Fig. 5).

Association between cisplatin response and p53 expression. Platinum-based chemotherapy is currently the standard first-line treatment for SCC, and most patients in the study had received cisplatin. To further characterize the established xenograft models, the third-generation xenograft tumors from 12 representative patients were treated with cisplatin. Fig. 6 presents the growth curves of the 12 xenograft tumors treated with cisplatin or saline, and the results show that 7 of 12 xenograft tumors were responsive to cisplatin chemotherapy (response rate 58\%) while the remaining 5 were resistant. Furthermore, the expression of p53 was positive in 4 of 5 nonresponding tumors and negative in 6 of 7 responding tumors (Table VII), indicating the benefit of administrating cisplatin-based adjuvant chemotherapy according to the expression status of $\mathrm{p} 53$.

Altered tissue structure and downregulated Ki-67 expression in tumors responsive to cisplatin. Histologic changes after chemotherapy were analyzed in xenograft tumors, and showed that the segmental tumor tissue in xenograft tumors responsive to cisplatin chemotherapy was replaced by scar tissue or necrosis, with the remaining cancer cells generally characterized by foamy cytoplasm. Moreover, IHC staining with anti-Ki-67 antibody showed that the proportion of Ki-67 stained tumor cells was dramatically decreased compared with controls $(39.3 \pm 27.5$ vs. $84.3 \pm 7.3, \mathrm{P}<0.01)$, indicating reduced cell proliferation. In contrast, cancer cells in nonresponding tumors had few histologic changes compared with controls and the expression of Ki-67 was not significantly affected by cisplatin chemotherapy $(85.0 \pm 5.0$ vs. $91.0 \pm 4.2)$ (Fig. 7).

Comparison of tumor responses in mice with clinical outcome of patients. Given that none of the SCC patients had received chemotherapy prior to surgery, individual comparison of clinical and xenograft outcomes could not be performed. Nevertheless, following surgical resection, the survival times of donor patients were followed up for a minimum of 2 years (Table VII). Among the 12 patients, 9 received adjuvant platinum-based (cisplatin/carboplatin + gemcitabine/docetaxel/vinorelbine) chemotherapy and 3 were lost to follow-up. Xenografts from 4 of 5 patients who developed recurrence during the 2-year follow-up were nonresponsive in mice. Four patients who had survived at the 2 -year follow-up were responsive to chemotherapy in mice.

\section{Discussion}

In this study, a total of 37 fresh SCC tissues were directly transplanted into athymic nude mice, and 18 PDTX models were successfully established. However, our success rate $(48.6 \%)$ was lower than that reported previously $(64 \%$, 29/45) (6) This difference may be attributable to sample size and the use of different mice strains, as this previous study used more severely immunocompromised mice (NOD/SCID, lacking functional T-, B-, and NK cells). However, studies with neuroblastoma patient-derived xenografts have shown that lymphoid cells and lymphatic vessels were present in PDTXs grown in athymic nude mice but not in NOD/SCID mice. Therefore, the choice of mouse strain dictated tumor microenvironmental components, which are implicated as crucial mediators of tumor growth, metastasis, and therapeutic responses and resistance (25).

The relationship between SCC engraftment in nude mice and clinicopathological parameters of patients was analyzed retrospectively, and we found that tumor volume and differentiation were closely correlated with the take rate of PDTXs, which was similar to that of a prior study in NSCLC (6) In addition, our results showed that the expression of $\mathrm{Ki} 67$ in original SCC patient tumors was a predictive factor for implanted tumor growth and the success of serial passages in PDTX mice, as reported previously for prostate cancer and hepatic metastasis uveal melanoma $(26,27)$. Moreover we observed that the average time for xenograft tumors to reach a volume of $500 \mathrm{~mm}^{3}$ in the first generation was longer than that of the other two passages (9.2,6.8 and 6.3 weeks, respectively), which suggested that passaging xenograft tumors were more proliferative than first-generation tumors and that PDTXs increased cancer cell proliferative activity, as reported previously in human malignant pleural mesothelioma (28).

To determine the histological and immunophenotypic features of the primary and xenograft tumors, 12 primary tumors and their corresponding xenograft tumors were analyzed by H\&E and IHC. The majority of xenograft tumors 
A
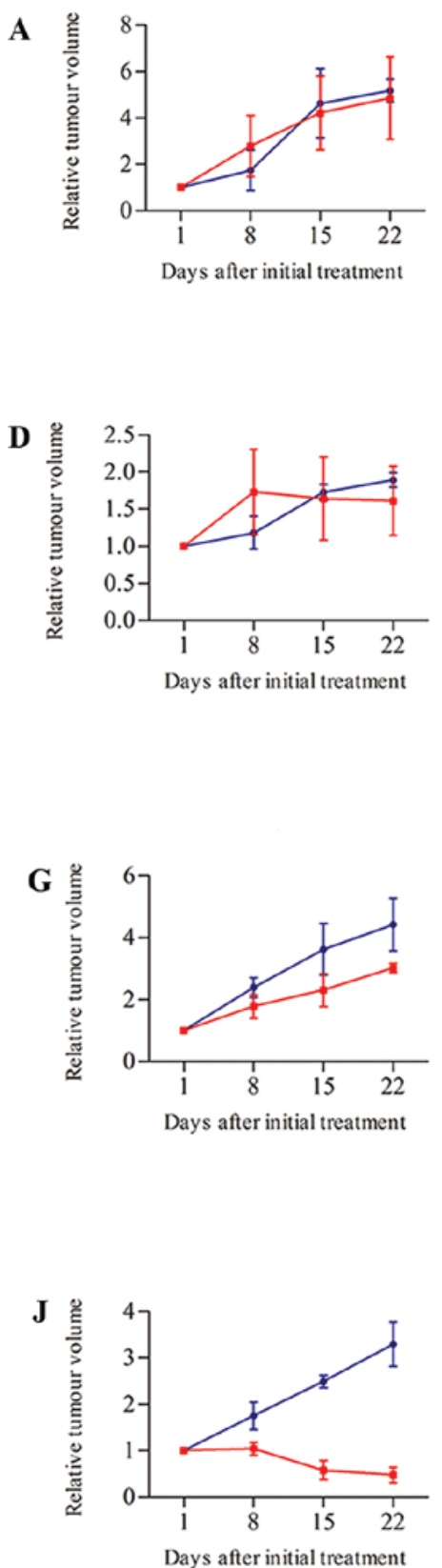

B

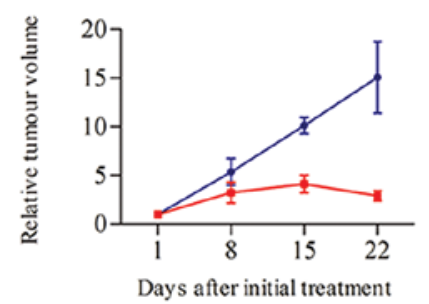

E

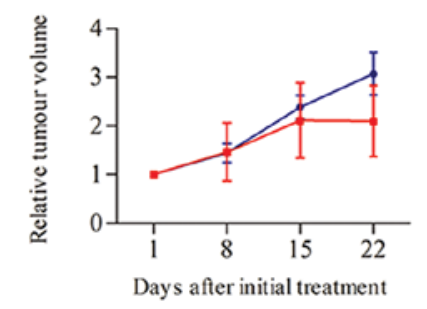

H
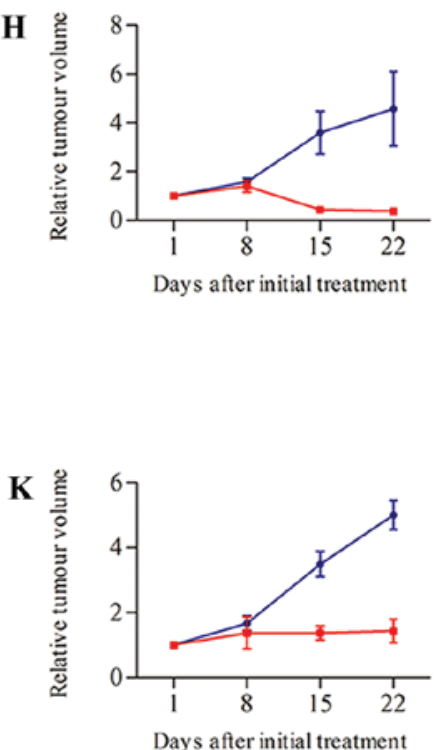

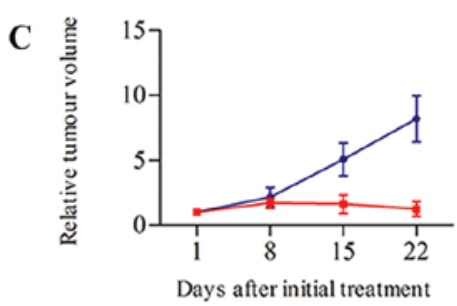

F
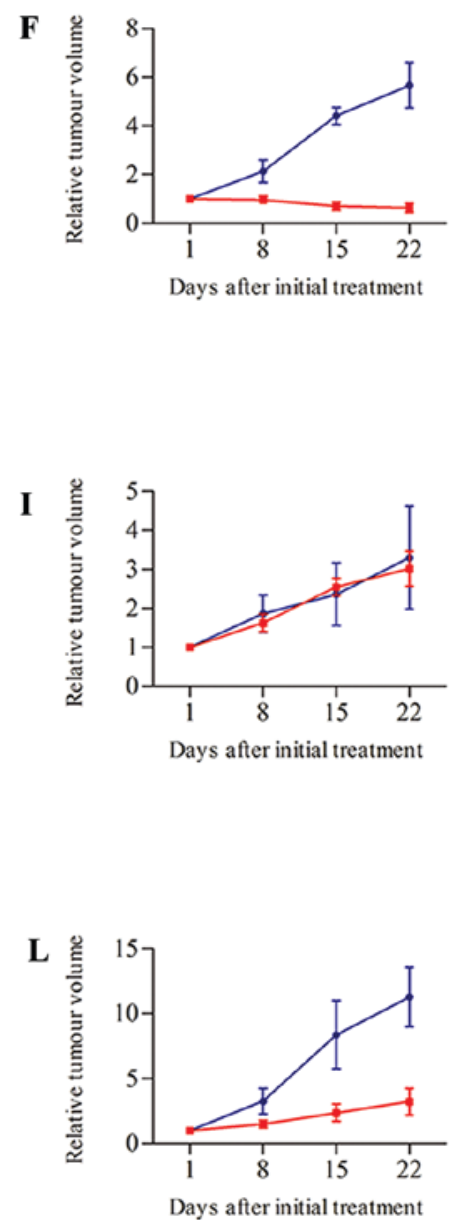

Figure 6. Therapeutic response of PDTXs treated with cisplatin or saline. Cispaltin (red) was administered at a dose of $5 \mathrm{mg} / \mathrm{kg}$ every week. Mice in the control group (blue) were injected with the same volumes of saline. Mice were treated weekly for 3 wk (i.p.). Treatment started when subcutaneous growing tumor volumes were $50-200 \mathrm{~mm}^{3}$; tumor volume and RTV were calculated as described in materials and methods; growth curves were obtained by plotting mean RTV against time. Compared with control groups, 7 of 12 xenograft tumors were responsive to cisplatin chemotherapy (B, C, F, H, J, K and L), the others (A, D, E, G and I) were resistant. Error bars represent calculated standard deviation. PDTX, patient-derived tumor xenograft; RTV, relative tumor volume.

maintained the histological and key immunophenotypic features of the primary tumor, with the exception of case 15 , which showed strong expression of $\mathrm{p} 63$ and cytokeratin $5 / 6$ by IHC in the primary tumor which decreased in corresponding passaging xenograft tumors, possibly because of the high heterogeneity of SCC. Additionally, variations in the expression of Ki-67 were observed. In some primary tumors (cases 2, 9, 10, 11, 14 and 15) the average proportion of Ki-67 stained tumor cells was $41.7 \pm 8.8 \%$, but was significantly elevated in first-generation xenograft tumors and maintained during serial passaging $(75.0 \pm 14.0,74.2 \pm 15.6$ and $83.3 \pm 7.5 \%$, respectively). Third-generation xenograft tumors had a further increased expression of Ki-67 (83.3 $\pm 7.5 \%)$, indicating a tendency to select for more rapidly-growing cells during the engraftment process, as reported previously in PDTX models for urothelial cancer (29). This result may partially explain why the growth of xenograft tumors in mice was faster in serial passages.

The global profiling of human lncRNA and mRNA expression patterns in the SCC specimens and the corresponding third-generation xenograft tumors were evaluated by microarray analysis. The calculated correlation coefficients showed a high concordance of gene expression between the third-generation xenograft tumors and the corresponding primary tumors. However, all 6 third-generation xenograft tumors clustered together within the primary tumors by unsupervised hierarchical clustering, demonstrating that the 
Table VII. Comparison of clinical outcome (post-operatively treated with platinum-based regime) with responses of xenografts to cisplatin.

\begin{tabular}{|c|c|c|c|c|c|c|}
\hline \multirow[b]{2}{*}{ Cases } & \multicolumn{4}{|c|}{ Patients } & \multicolumn{2}{|c|}{ Xenografts } \\
\hline & TNM stage & Treatment regimes & Clinical outcome & $\begin{array}{l}\text { Disease-free } \\
\text { time }(\mathrm{mo})\end{array}$ & p53 protein & $\begin{array}{l}\text { Response to } \\
\text { cisplatin (n) }\end{array}$ \\
\hline 1 & T3N0M0 & $\begin{array}{l}\text { Cisplatin } 75 \mathrm{mg} / \mathrm{m}^{2} \text {, } \\
\text { day } 1+\text { vinorelbine } 30 \mathrm{mg} / \mathrm{m}^{2} \text {, } \\
\text { day } 1,8 \text {, every } 21 \text { days, } 4 \text { cycle }\end{array}$ & Recurrence & 11.4 & Positive & NR (6) \\
\hline 2 & T3N0M0 & $\begin{array}{l}\text { Cisplatin } 75 \mathrm{mg} / \mathrm{m}^{2} \text {, } \\
\text { day } 1+\text { gemcitabine } 1,000 \mathrm{mg} / \mathrm{m}^{2}, \\
\text { day } 1,8 \text {, every } 21 \text { days, } 3 \text { cycle }\end{array}$ & No recurrence & $>41.0$ & Negative & $\mathrm{R}(81)$ \\
\hline 3 & T4N2M0 & - & - & Lost in follow-up & Negative & $\mathrm{R}(85)$ \\
\hline 4 & T3N0M0 & $\begin{array}{l}\text { Cisplatin } 75 \mathrm{mg} / \mathrm{m}^{2} \text {, } \\
\text { day } 1+\text { gemcitabine } 1,000 \mathrm{mg} / \mathrm{m}^{2}, \\
\text { day } 1,8 \text {, every } 21 \text { days, } 3 \text { cycle }\end{array}$ & Recurrence & 4.8 & Positive & NR (41) \\
\hline 6 & T2N0M0 & - & - & Lost in follow-up & Negative & NR (32) \\
\hline 9 & T3N0M0 & $\begin{array}{l}\text { Carboplatin } 300 \mathrm{mg} / \mathrm{m}^{2} \text {, } \\
\text { day } 1+\text { gemcitabine } 1,000 \mathrm{mg} / \mathrm{m}^{2}, \\
\text { day } 1,8 \text {, every } 21 \text { days, } 2 \text { cycle }\end{array}$ & Recurrence & 2.4 & Positive & R (89) \\
\hline 10 & T4N0M0 & $\begin{array}{l}\text { Cisplatin } 75 \mathrm{mg} / \mathrm{m}^{2}, \\
\text { day } 1+\text { gemcitabine } 1,000 \mathrm{mg} / \mathrm{m}^{2} \\
\text { day } 1,8, \text { every } 21 \text { days, } 3 \text { cycle }\end{array}$ & Recurrence & 8.6 & Positive & NR (32) \\
\hline 11 & T3N2M0 & $\begin{array}{l}\text { Cisplatin } 75 \mathrm{mg} / \mathrm{m}^{2} \text {, day } 1+\text { docetaxel } \\
75 \mathrm{mg} / \mathrm{m}^{2} \text {, day } 1 \text { every } 21 \text { days, } 3 \text { cycle }\end{array}$ & No recurrence & $>35.0$ & Negative & $\mathrm{R}(92)$ \\
\hline 12 & T3N1M0 & $\begin{array}{l}\text { Cisplatin } 75 \mathrm{mg} / \mathrm{m}^{2} \text {, day } 1+\text { gemcitabine } \\
1,000 \mathrm{mg} / \mathrm{m}^{2} \text {, day } 1,8 \text {, every } 21 \text { days, } \\
1 \text { cycle }\end{array}$ & Recurrence & 4.5 & Positive & NR (9) \\
\hline 13 & $\mathrm{~T} 2 \mathrm{~N} 2 \mathrm{M} 0$ & $\begin{array}{l}\text { Carboplatin } 300 \mathrm{mg} / \mathrm{m}^{2}, \\
\text { day } 1+\text { gemcitabine } 1,000 \mathrm{mg} / \mathrm{m}^{2} \\
\text { day } 1,8 \text {, every } 21 \text { days, } 3 \text { cycle }\end{array}$ & No recurrence & $>32.0$ & Negative & R (86) \\
\hline 14 & T2N0M0 & - & - & Lost in follow-up & Negative & $\mathrm{R}(72)$ \\
\hline 15 & T2N0M0 & $\begin{array}{l}\text { Cisplatin } 75 \mathrm{mg} / \mathrm{m}^{2} \text {, } \\
\text { day } 1+\text { gemcitabine } 1,000 \mathrm{mg} / \mathrm{m}^{2}, \\
\text { day } 1,8 \text {, every } 21 \text { days, } 3 \text { cycle }\end{array}$ & No recurrence & $>28.0$ & Negative & $\mathrm{R}(71)$ \\
\hline
\end{tabular}

NR, non-responding; R, responding; TNM, tumor node metastasis.

xenograft tumors were more similar to each other than to the primary tumors. These results indicated that, despite similarities, there were also changes to a certain extent in the RNA expression of xenograft tumors (including lncRNAs and mRNAs) compared with primary tumors. Because the stroma in the xenograft tumor was largely replaced by murine stroma, as expected, GO and pathway analysis showed that decreased mRNAs in third xenograft tumors might be mainly involved in immune-mediated processes, consistent with previous reports $(30,31)$. In addition, increased expression of mRNAs mainly involved in the regulation of cell cycle and metabolic processes in the third-generation xenograft tumors was consistent with the study of Wang et al (32). Their results showed that genomic alterations in cell cycle pathways were the most frequently found changes in PDTXs of NSCLC. In a similar study with proteomic characterization of head and neck cancer (33), proteins associated with proliferative signaling appeared to be preferentially selected during the process of creating PDTXs. Taken together, changes in cell proliferation and immune-mediated processes may represent an important reason for the faster growth of xenograft tumors in serial passages. Moreover, we found that lncRNA expression was altered in xenograft tumors. It seems likely that some of the separation seen in the lncRNA clustering analysis reflects variations in tumor stroma. Furthermore, the functions of many of the differentially expressed lncRNAs observed in our study have not yet been established, and it is possible that they do not significantly impact carcinoma phenotype. However, whether they influence cell proliferation and immune-mediated processes needs to be explored. Similarly, the mRNA profile in lung cancer xenograft tumors has previously been shown to differ from that of original tumors (34).

Given the alterations in cell cycle and metabolic processes of xenograft tumors, and the faster growth of xenograft tumors in 
A a-1

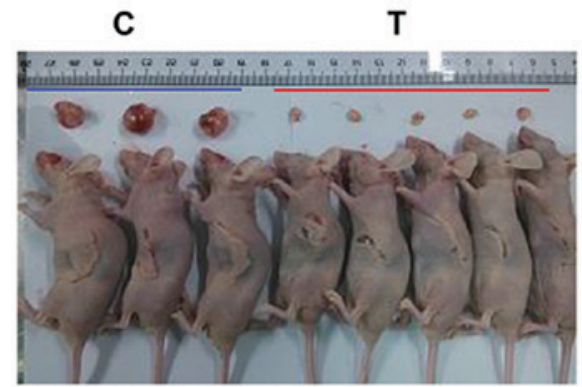

a-2

\section{H\&E}

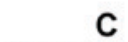

c

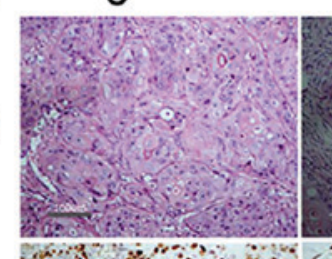

T
B b-1

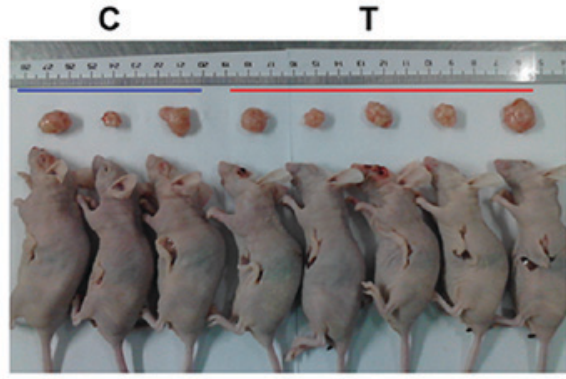

b-2

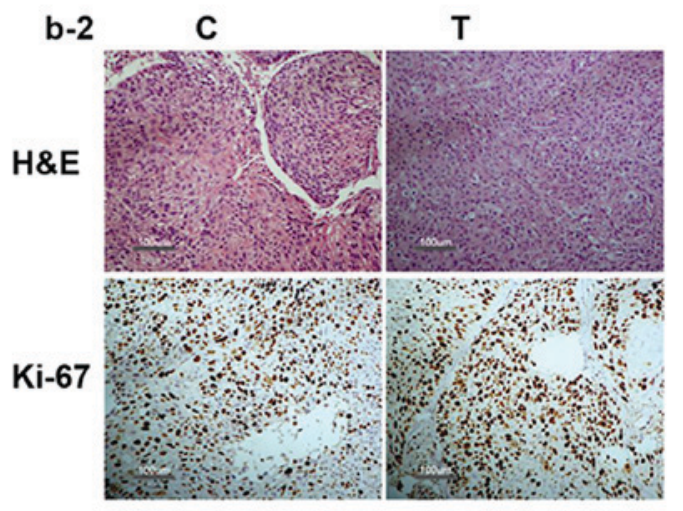

a-3

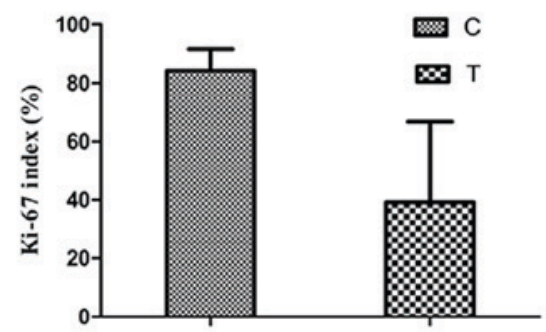

b-3

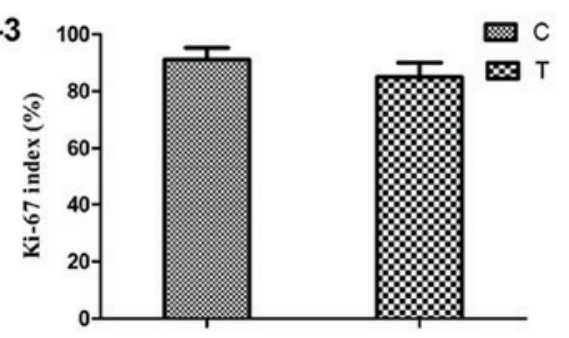

Figure 7. Tissue sections of one (A) chemo-responsive and (B) nonresponsive PDTXs. Compared with control group, tumor volume of the cisplatin treated group was dramatically reduced in chemo-responsive PDTX (a-1), which was not seen in nonresponsive PDTX (b-1). Cisplatin treated group was replaced by scar tissue or necroses showing fewer viable tumor cells with clear foamy (arrow) cytoplasm and reduced Ki-67 in chemo-responsive PDTX (a-2) but not in nonresponsive PDTX (b-2). Cisplatin-induced changes in Ki-67 indices was significant in chemo-responsive tumor (a-3, 39.3 \pm 27.5 vs. $84.3 \pm 7.3$, $\mathrm{P}<0.01)$ but not in nonresponsive tumor (b-3, $85.0 \pm 5.0$ vs. $91.0 \pm 4.2, \mathrm{P}>0.05)$. C represents the third generation xenografts treated with saline; $\mathrm{T}$ represents the third generation xenografts treated with cisplatin. Scale bars, $100 \mu \mathrm{m}$.

serial passages, proliferation and DNA synthesis in xenografts may be faster than that of primary tumors. Platinum-based chemotherapy is the first-line treatment for SCC. Platinum-based drugs bind to nuclear DNA, forming a variety of structural adducts and triggering cellular apoptosis $(35,36)$. We therefore hypothesize that changes in cell proliferation may affect the response to platinum-based chemotherapy. To test this hypothesis, we investigated the responses of 12 established third-generation xenograft tumors to single cisplatin treatments, and found that $60 \%$ of the tumors were responsive and that chemotherapy-induced histologic changes in third-generation xenograft tumors were consistent with changes documented previously in clinical studies in NSCLC specimens following preoperative chemotherapy (37). Secondly, the International Adjuvant Lung Cancer Trial (IALT) demonstrated that cell cycle regulators (p16INK4A, cyclin D1, cyclin D3, cyclin E) and $\mathrm{Ki}-67$ did not predict the benefit of adjuvant cisplatin-based chemotherapy in NSCLC patients, except for p27Kip1 (38). However, in our study, when compared with primary tumors, the mRNA expression of p27Kip1 was not changed in the 6 third-generation xenograft tumors. In addition, we found that the response rates to cisplatin-based chemotherapy in xenograft tumors related to the expression status of $\mathrm{p} 53$, which was positive in 4 of 5 non-responding tumors and negative in 6 of 7 responding tumors. Similarly, p53 was assessed using IHC in a large subset of NSCLC patients $(n=769)$ from the IALT trial who had received cisplatin-based chemotherapy. The results suggested that $\mathrm{p} 53$ was predictive of a cisplatin-based therapeutic benefit in patients with SCC but not ADC (39). As none of the SCC donors in our study had received chemotherapy prior to surgery, individual comparison of clinical and xenograft outcomes could not be performed. However, the differential responses of the 12 observed xenograft tumors to the individual cisplatin drug treatments would strongly justify an individual prediction of responsiveness. Moreover, we compared tumor responses in xenograft tumors with clinical outcomes of patients who received platinum-based chemotherapy after surgery, and the results suggested that four patients had survived to the 2-year follow-up and that the corresponding third-generation xenograft tumors were responsive to cisplatin chemotherapy. Xenograft tumors from four of five patients who developed recurrence were nonresponsive in mice. Nevertheless, in view of the small number of SCC patients included, further studies are required to verify this observation. 
In conclusion, we evaluated the characteristics of SCC xenograft tumors in this study, and our findings suggest that these tumors closely resembled the original tumor and largely retained key immunophenotypic features. Moreover, we showed that LSCC xenografting altered tumor cell proliferation but maintained the responsiveness to platinum-based chemotherapy. In expression profiling of human IncRNAs and mRNAs, however, xenografts clustered separately from the original tumors. This result suggests that lncRNA and mRNA expression may be altered in xenografts, a possibility which warrants further investigation.

\section{Acknowledgments}

Not applicable.

\section{Funding}

This study was supported by Province science and technology in the Anhui offends pass item (no. 1604a0802072, 2016), Natural Science Foundation of Anhui province, China (no. 1708085QH220, 2017), National Natural Science Foundation of China (no. 81172172, 2011).

\section{Availability of data and materials}

The datasets generated or analyzed during the current study are available from the corresponding author upon written request.

\section{Authors' contributions}

BW designed the study and participated in writing the manuscript and approved the final version of the manuscript to be published. JZ, YY, QW, ML, HZ and MX performed the laboratory work. DL and PL contributed to the acquisition, analysis and interpretation of data for the study, and participated in writing the manuscript. JZ, YY and QW participated in designing the statistical analysis and preparing the manuscript. ML, HZ and MX participated in designing the study and provided clinical data. All authors contributed to the manuscript and approved the final version of it.

\section{Ethics approval and consent to participate}

Tumor samples and clinical records were obtained from patients with their written informed consent and the study was approved by Anhui Provincial Hospital Ethical Committee. Consent was obtained to publish from the participant to report individual patient data. All animal experiments were approved by Anhui Provincial Hospital Ethical Committee and were carried out in accordance with Guidelines for the Care and Use of Laboratory Animals.

\section{Consent for publication}

Consent for publication was obtained through the Institutional Review Board approved protocol with an institutional consent form.

\section{Competing interests}

The authors declare that there are no competing interests.

\section{References}

1. Chen W, Zheng R, Baade PD, Zhang S, Zeng H, Bray F, Jemal A, Yu XQ and He J: Cancer statistics in China, 2015. CA Cancer J Clin 66: 115-132, 2016.

2. Jemal A, Bray F, Center MM, Ferlay J, Ward E and Forman D: Global cancer statistics. CA Cancer J Clin 61: 69-90, 2011.

3. Torre LA, Bray F, Siegel RL, Ferlay J, Lortet-Tieulent J and Jemal A: Global cancer statistics, 2012. CA Cancer J Clin 65: 87-108, 2015.

4. Pikor LA, Ramnarine VR, Lam S and Lam WL: Genetic alterations defining NSCLC subtypes and their therapeutic implications. Lung Cancer 82: 179-189, 2013.

5. Kerbel RS: Human tumor xenografts as predictive preclinical models for anticancer drug activity in humans: Better than commonly perceived-but they can be improved. Cancer Biol Ther 2 (4 Suppl 1): S134-S139, 2003.

6. John T, Kohler D, Pintilie M, Yanagawa N, Pham NA, Li M, Panchal D, Hui F, Meng F, Shepherd FA and Tsao MS: The ability to form primary tumor xenografts is predictive of increased risk of disease recurrence in early-stage non-small cell lung cancer. Clin Cancer Res 17: 134-141, 2011.

7. Lin D, Wyatt AW, Xue H, Wang Y, Dong X, Haegert A, Wu R, Brahmbhatt S, Mo F, Jong L, et al: High fidelity patient-derived xenografts for accelerating prostate cancer discovery and drug development. Cancer Res 74: 1272-1283, 2014.

8. Johnson JI, Decker S, Zaharevitz D, Rubinstein LV, Venditti JM, Schepartz S, Kalyandrug S, Christian M, Arbuck S, Hollingshead M and Sausville EA: Relationships between drug activity in NCI preclinical in vitro and in vivo models and early clinical trials. Br J Cancer 84: 1424-1431, 2001.

9. Garber K: From human to mouse and back: 'tumorgraft' models surge in popularity. J Natl Cancer Inst 101: 6-8, 2009.

10. Dong X, Guan J, English JC, Flint J, Yee J, Evans K, Murray N, Macaulay C, Ng RT, Gout PW, et al: Patient-derived first generation xenografts of non-small cell lung cancers: promising tools for predicting drug responses for personalized chemotherapy. Clin Cancer Res 16: 1442-1451, 2010.

11. Perez-Soler R, Kemp B, Wu QP, Mao L, Gomez J, Zeleniuch-Jacquotte A, Yee H, Lee JS, Jagirdar J and Ling YH: Response and determinants of sensitivity to paclitaxel in human non-small cell lung cancer tumors heterotransplanted in nude mice. Clin Cancer Res 6: 4932-4938, 2000.

12. Hao C, Wang L, Peng S, Cao M, Li H, Hu J, Huang X, Liu W, Zhang $\mathrm{H}$, Wu S, et al: Gene mutations in primary tumors and corresponding patient-derived xenografts derived from non-small cell lung cancer. Cancer Lett 357: 179-185, 2015.

13. Cech TR and Steitz JA: The noncoding RNA revolution-trashing old rules to forge new ones. Cell 157: 77-94, 2014.

14. Guttman M, Russell P, Ingolia NT, Weissman JS and Lander ES: Ribosome profiling provides evidence that large noncoding RNAs do not encode proteins. Cell 154: 240-251, 2013.

15. Geisler S and Coller J: RNA in unexpected places: Long non-coding RNA functions in diverse cellular contexts. Nat Rev Mol Cell Bio 14: 699-712, 2013.

16. Wilusz JE, Sunwoo H and Spector DL: Long noncoding RNAs: Functional surprises from the RNA world. Genes Dev 23: 1494-1504, 2009.

17. Gupta RA, Shah N, Wang KC, Kim J, Horlings HM, Wong DJ, Tsai MC, Hung T, Argani P, Rinn JL, et al: Long non-coding RNA HOTAIR reprograms chromatin state to promote cancer metastasis. Nature 464: 1071-1076, 2010.

18. Sun M, Nie FQ, Wang YF, Zhang Z, Hou J, He D, Xie M, Xu L, De W, Wang Z and Wang J: LncRNA HOXA11-AS promotes proliferation and invasion of gastric cancer by scaffolding the chromatin modification factors PRC2, LSD1, and DNMT1. Cancer Res 76: 6299-6310, 2016.

19. Yuan JH, Liu XN, Wang TT, Pan W, Tao QF, Zhou WP, Wang F and Sun SH: The MBNL3 splicing factor promotes hepatocellular carcinoma by increasing PXN expression through the alternative splicing of lncRNA-PXN-AS1. Nat Cell Biol 19: 820-832, 2017.

20. Gutschner T, Hämmerle M, Eissmann M, Hsu J, Kim Y, Hung G, Revenko A, Arun G, Stentrup M, Gross M, et al: The noncoding RNA MALAT1 is a critical regulator of the metastasis phenotype of lung cancer cells. Cancer Res 73: 1180-1189, 2013.

21. Wu Y, Lyu H, Liu H, Shi X, Song Y and Liu B: Downregulation of the long noncoding RNA GAS5-AS1 contributes to tumor metastasis in non-small cell lung cancer. Sci Rep 6: 31093, 2016. 
22. Gao S, Lin Z, Li C, Wang Y, Yang L, Zou B, Chen J, Li J, Song Z and Liu G: TFPI2AS1, a novel lncRNA that inhibits cell proliferation and migration in lung cancer. Cell Cycle 16: 2249-2258, 2017.

23. Livak KJ and Schmittgen TD: Analysis of relative gene expression data using real-time quantitative PCR and the 2(-Delta Delta $\mathrm{C}(\mathrm{T})$ ) method. Methods 25: 402-408, 2001.

24. Julien S, Merino-Trigo A, Lacroix L, Pocard M, Goéré D, Mariani P, Landron S, Bigot L, Nemati F, Dartigues P, et al: Characterization of a large panel of patient-derived tumor xenografts representing the clinical heterogeneity of human colorectal cancer. Clin Cancer Res 18: 5314-5328, 2012.

25. Braekeveldt N, Wigerup C, Tadeo I, Beckman S, Sandén C, Jönsson J, Erjefält JS, Berbegall AP, Börjesson A Backman $\mathrm{T}$ et al: Neuroblastoma patient-derived orthotopic xenografts reflect the microenvironmental hallmarks of aggressive patient tumours. Cancer Lett 375: 384-389, 2016.

26. Lawrence MG, Pook DW, Wang H, Porter LH, Frydenberg M, Kourambas J, Appu S, Poole C, Beardsley EK, Ryan A, et al Establishment of primary patient-derived xenografts of palliative TURP specimens to study castrate-resistant prostate cancer. Prostate 75: 1475-1483, 2015.

27. Kageyama K, Ohara M, Saito K, Ozaki S, Terai M, Mastrangelo MJ, Fortina P, Aplin AE and Sato T: Establishment of an orthotopic patient-derived xenograft mouse model using uveal melanoma hepatic metastasis. J Transl Med 15: 145, 2017.

28. Wu LC, Allo G, John T, Li M, Tagawa T, Opitz I, Anraku M, Yun Z, Pintilie M, Pitcher B, et al: Patient-derived xenograft establishment from human malignant pleural mesothelioma. Clin Cancer Res 23: 1060-1067, 2017.

29. Abe T, Tada M, Shinohara N, Okada F, Itoh T, Hamada J, Harabayashi T, Chen Q, Moriuchi T and Nonomura K: Establishment and characterization of human urothelial cancer xenografts in severe combined immunodeficient mice. Int $\mathrm{J}$ Urol 13: 47-57, 2006.

30. Fichtner I, Rolff J, Soong R, Hoffmann J, Hammer S, Sommer A, Becker M and Merk J: Establishment of patient-derived non-small cell lung cancer xenografts as models for the identification of predictive biomarkers. Clin Cancer Res 14: 6456-6468, 2008

31. Reyal F, Guyader C, Decraene C, Lucchesi C, Auger N, Assayag F, De Plater L, Gentien D, Poupon MF, Cottu P, et al: Molecular profiling of patient-derived breast cancer xenografts. Breast Cancer Res 14: R11, 2012.
32. Wang D, Pham NA, Tong JF, Sakashita S, Allo G, Kim L, Yanagawa N, Raghavan V, Wei Y, To C, et al: Molecular heterogeneity of non-small cell lung carcinoma patient-derived xenografts closely reflect their primary tumors. Int J Cancer 140: 662-673, 2017.

33. Li H, Wheeler S, Park Y, Ju Z, Thomas SM, Fichera M, Egloff AM, Lui VW, Duvvuri U, Bauman JE, et al: Proteomic characterization of head and neck cancer patient-derived xenografts. Mol Cancer Res 14: 278-286, 2016.

34. Bogner PN, Patnaik SK, Pitoniak R, Kannisto E, Repasky E, Hylander B, Yendamuri S and Ramnath N: Lung cancer xenografting alters microRNA profile but not immunophenotype. Biochem Biophys Res Commun 386: 305-310, 2009.

35. Crino L, Weder W, van Meerbeeck J and Felip E; ESMO Guidelines Working Group: Early stage and locally advanced (non-metastatic) non-small-cell lung cancer: ESMO clinical practice guidelines for diagnosis, treatment and follow-up. Ann Oncol 21 (Suppl 5): v103-v115, 2010.

36. Azzoli CG, Temin S, Aliff T, Baker S Jr, Brahmer J, Johnson DH, Laskin JL, Masters G, Milton D, Nordquist L, et al: 2011 focused update of 2009 American society of clinical oncology clinical practice guideline update on chemotherapy for stage IV non-small-cell lung cancer. J Clin Oncol 29: 3825-3831, 2011

37. Junker K: Therapy-induced tumor regression and regression grading in lung cancer. Pathologe 35: 574-577, 2014 (In German)

38. Filipits M, Pirker R, Dunant A, Lantuejoul S, Schmid K, Huynh A, Haddad V, André F, Stahel R, Pignon JP, et al: Cell cycle regulators and outcome of adjuvant cisplatin-based chemotherapy in completely resected non-small-cell lung cancer: The international adjuvant lung cancer trial biologic program. J Clin Oncol 25: 2735-2740, 2007.

39. Pierceall WE, Olaussen KA, Rousseau V, Brambilla E, Sprott KM, Andre F, Pignon JP, Le Chevalier T, Pirker R, Jiang C, et al: Cisplatin benefit is predicted by immunohistochemical analysis of DNA repair proteins in squamous cell carcinoma but not adenocarcinoma: Theranostic modeling by NSCLC constituent histological subclasses. Ann Oncol 23: 2245-2252, 2012.

(i) (5) This work is licensed under a Creative Commons (c) ${ }_{\mathrm{EY}} \mathrm{No} \mathrm{ND}$ Attribution-NonCommercial-NoDerivatives 4.0 International (CC BY-NC-ND 4.0) License. 